\title{
Abnormal Vitamin D Metabolism, Intestinal Calcium Transport, and Bone Calcium Status in the Spontaneously Hypertensive Rat Compared with Its Genetic Control
}

\author{
P. A. Lucas, R. C. Brown, “ T. Drüeke, B. Lacour, J. A. Metz, $¥$ and D. A. McCarron¥ \\ Institut National de la Santé et de la Recherche Médicale, Unité 90, Département de Néphrologie, Hôpital Necker, Paris, France; \\ *Department of Medical Biochemistry, University of Wales College of Medicine, Cardiff, Wales, United Kingdom; \\ $\ddagger$ Division of Nephrology and Hypertension, Oregon Health Sciences University, Portland, Oregon 97201
}

\begin{abstract}
Abnormalities of intestinal calcium absorption and the vitamin $D$ axis in the spontaneously hypertensive rat (SHR) are controversial. The present report documents a reduction in circulating 1,25-dihydroxyvitamin $D_{3}\left(1,25(\mathrm{OH})_{2} D_{3}\right)$ in the 12-14-wk-old male SHR with evidence of its functional significance. Both plasma $1,25(\mathrm{OH})_{2} \mathrm{D}_{3}$ and mucosa-to-serosa duodenal calcium flux $\left(J_{\mathrm{m}-\mathrm{s}}\right)$, measured by the Ussing chamber, were significantly lower ( $\sim 60 \%$ of value in Wistar-Kyoto rats [WKY]) in SHR on both normal $(1 \%)$ and low $(0.1 \%)$ calcium diets than in corresponding control WKY. Low dietary calcium increased both $1,25(\mathrm{OH})_{2} \mathrm{D}_{3}$ and $J_{\mathrm{m}-\mathrm{s}}$ by $\sim 80 \%$ in SHR and WKY, with levels of both parameters rising in the SHR to levels found in the WKY under baseline conditions. The latter fact suggests the improbability of intestinal resistance to the action of $1,25(\mathrm{OH})_{2} \mathrm{D}_{3}$ in the SHR. Plasma 25-hydroxyvitamin $D_{3}\left(25(O H) D_{3}\right)$ was not significantly different between the strains. Intraperitoneal $1,25(\mathrm{OH})_{2} D_{3}$ increased $J_{\mathrm{m}-\mathrm{s}}$ in 12-14-wk-old SHR to levels observed in equivalent WKY. In 20-24-wk-old SHR, calcium deprivation was associated with significantly reduced $J_{\mathbf{m}-\mathbf{s}}$ compared with equivalent WKY. Bone density and bone calcium content in 20-30-wk-old SHR were significantly reduced. In summary, we provide evidence that the SHR was unable to sustain appropriate circulating levels of $1,25(\mathrm{OH})_{2} \mathrm{D}_{3}$, an impairment which resulted in reduced duodenal calcium absorption.
\end{abstract}

\section{Introduction}

In a variety of experimental systems, the spontaneously hypertensive rat (SHR) ${ }^{1}$ has been shown to exhibit abnormalities in calcium metabolism (1-5). Intestinal calcium transport has been studied in the SHR by several investigators using a variety of methods and found to be either increased $(6,7)$, unchanged $(8)$, or decreased $(7,9)$ compared with its normotensive control, the Wistar-Kyoto rat (WKY). However, the considerable diversity in diets administered, as well as differences in age and sex of animals investigated, has made effective comparison of the stud-

Address reprint requests to Dr. Lucas, INSERM U90, Département de Néphrologie, Hôpital Necker, 161, rue de Sèvres, 75743 Paris Cedex 15, France.

Received for publication 29 October 1985 and in revised form 31 March 1986.

1. Abbreviations used in this paper: $\mathrm{BMC} / \mathrm{W}$, bone mineral content/ femur width; PD, potential difference; SHR, spontaneous hypertensive rat(s); WKY, Wistar Kyoto rat(s).

J. Clin. Invest.

(C) The American Society for Clinical Investigation, Inc. 0021-9738/86/07/0221/07 \$1.00

Volume 78, July 1986, 221-227 ies difficult. The important questions as to the integrity of the vitamin $D$ endocrine system and the possibility of intestinal resistance to the action of 1,25-dihydroxyvitamin $D_{3}$ $\left(1,25(\mathrm{OH})_{2} \mathrm{D}_{3}\right)$ have been raised by several investigators (6-9), but a consensus has yet to emerge.

We have recently reported our use of the modified Ussing chamber to obtain a precise measure of $1,25(\mathrm{OH})_{2} \mathrm{D}_{3}$-dependent active calcium transport in the SHR (10). Both mucosa-to-serosa flux $\left(J_{\text {m-s }}\right)$ and net flux $\left(J_{\text {net }}\right)$ were significantly reduced in the duodenum-proximal jejunum of the 12-14-wk-old SHR as compared with the WKY.

In the present study, we have confirmed this finding and extended it by investigating calcium transport under conditions of normal and reduced dietary calcium intake in animals at two different stages of development. Moreover, we have determined serum $1,25(\mathrm{OH})_{2} \mathrm{D}_{3}$ concentrations in SHR and WKY subject to normal and reduced dietary calcium to evaluate the regulation of the vitamin $\mathrm{D}$ axis and to address the question of intestinal response to circulating $1,25(\mathrm{OH})_{2} \mathrm{D}_{3}$. Finally, bone densitometry and determinations of bone calcium content were carried out as indices of the overall calcium status of this experimental model of hypertension.

\section{Methods}

Animals. For the transport and vitamin D studies, male SHR and WKY were obtained at the age of 6 wk from IFFA CREDO (Centre de Recherche et d'Élevage des Oncins, L'Arbresle, France). Up to the time of receipt at the age of $6 \mathrm{wk}$, the animals received diets containing $2.0 \mathrm{IU} /$ $g$ vitamin $D_{3}, 0.66 \%$ phosphorus, and $0.75 \%$ calcium (\% dry weight). In all experiments described, the animals were maintained in well-lit rooms (12 h:12 h light/dark cycle) and allowed free access to food and water up to the time they were killed (transport studies) or underwent sampling (vitamin $\mathrm{D}_{3}$ metabolite determinations). SHR and WKY rats used for bone densitometry and bone calcium content determinations were obtained from Charles River Breeding Laboratories, Inc., (Boston, MA).

Vitamin $D_{3}$ metabolite determinations. Eight SHR and eight WKY rats were raised from the age of $6 \mathrm{wk}$ on a diet containing $0.45 \%$ sodium, $0.46 \%$ phosphorus, and $1.0 \%$ calcium (\% dry weight); $20 \%$ dietary protein as casein; vitamin $D_{2}, 2.2 \mathrm{IU} / \mathrm{g}$ food until the age of 12-14 wk. A further eight SHR and eight WKY were simultaneously raised on a low calcium diet $(0.1 \%$ calcium) otherwise identical to that taken by the first group. 3-5 $\mathrm{ml}$ of blood was obtained via the subclavian vein from each animal between 9 a.m. and 11 a.m. on two separate occasions, 1 wk apart. Sera were extracted and stored at $-70^{\circ} \mathrm{C}$ for subsequent 25 -hydroxyvitamin $\mathrm{D}_{3}\left(25(\mathrm{OH}) \mathrm{D}_{3}\right)$ and $1,25(\mathrm{OH})_{2} \mathrm{D}_{3}$ determinations.

Serum samples $(1 \mathrm{ml})$ were extracted according to the dual cartridge method of Kao and Heser (11). The $1,25(\mathrm{OH})_{2} \mathrm{D}_{3}$ fraction was further purified by normal-phase high-performance liquid chromatography (Partisil $5 \mu$ developed in hexane: 2 propanol:methanol 90:5:5 vol/vol/ vol). The eluant volume corresponding to $1,25(\mathrm{OH})_{2} \mathrm{D}_{3}$ was collected and the quantity of $1,25(\mathrm{OH})_{2} \mathrm{D}_{3}$ was measured by radioimmunoassay using antiserum 02282 . This antiserum does not cross-react with vitamin $D_{2}$ metabolites and displays approximately equal cross-reactivity with 
the major metabolites of vitamin $D_{3}$. It was also utilized as the ligand binding agent for the radioimmunoassay of the $25(\mathrm{OH}) \mathrm{D}_{3}$ fraction. Antiserum 02282 was kindly provided by Prof. A. D. Care, University of Leeds, United Kingdom. Results are expressed as the mean of two determinations per animal. Within-assay variations $(\mathrm{CV}$, coefficient of variation) (given as mean $\pm \mathrm{SD}$ ): $25(\mathrm{OH})_{2} \mathrm{D}_{3}$ assay: at $8.8 \mathrm{ng} / \mathrm{ml} \pm 0.76$, $\mathrm{CV}=8.6 \%, n=6$; at $27.2 \pm 1.47 \mathrm{ng} / \mathrm{ml}, \mathrm{CV}=5.4 \%, n=11.1,25(\mathrm{OH})_{2} \mathrm{D}_{3}$ assay: at $26.0 \mathrm{pg} / \mathrm{ml} \pm 4.0, \mathrm{CV}=15.6 \%, n=5$; at $58.5 \mathrm{pg} / \mathrm{ml} \pm 7.1, \mathrm{CV}$ $=12.8 \%, n=4$. Between-assay variations: $25(\mathrm{OH}) \mathrm{D}_{3}$ assay: at $7.4 \mathrm{ng} /$ $\mathrm{ml} \pm 0.6, \mathrm{CV}=8.3 \%, n=7$; at $24.5 \mathrm{ng} / \mathrm{ml} \pm 2.2, \mathrm{CV}=9.2 \%, n=9$. $1,25(\mathrm{OH})_{2} \mathrm{D}_{3}$ assay: at $29.1 \mathrm{pg} / \mathrm{ml} \pm 3.9, \mathrm{CV}=13.5 \%, n=9$; at 77.8 $\mathrm{pg} / \mathrm{ml} \pm 6.3, \mathrm{CV}=8.1 \%, n=10$.

Ussing chamber experiments. Intestinal transmural calcium fluxes were determined using the modified Ussing apparatus (12). Duodenal segments $10 \mathrm{~cm}$ in length, immediately distal to the pylorus, were dissected. The segments were then excised, opened along the mesenteric border and mounted unstripped in the modified Ussing chambers. Tissue apertures were $0.5 \mathrm{~cm}^{2}$. Tissues from SHR and WKY were studied in random order, the sequence of which was unknown to the operator.

The mounted intestinal segment was bathed in a phosphate-free Krebs-Ringer bicarbonate solution maintained at $\mathrm{pH} 7.4$ and $37^{\circ} \mathrm{C}\left(\mathrm{Na}^{+}\right.$ $145, \mathrm{~K}^{+} 4.7, \mathrm{Ca}^{2+} 1.25, \mathrm{Mg}^{2+} 1.2, \mathrm{Cl}^{-} 127.2, \mathrm{HCO}_{3}^{-} 25, \mathrm{SO}_{4}^{2-} 1.2, \mathrm{D}-$ glucose $11 \mathrm{mmol} /$ liter). Each hemichamber compartment contained 10 $\mathrm{ml}$ of electrolyte solution and was aerated with $95 \% \mathrm{O}_{2} / 5 \% \mathrm{CO}_{2}$ throughout the experiment. The solutions bathing the mucosal and serosal sides were connected via agar bridges to calomel electrodes for the direct measurement of the potential difference (PD) and to $\mathrm{Ag}-\mathrm{AgCl}$ electrodes for the passage of direct current through the tissue, using an automatic voltage clamp (dual-voltage clamp: $616 \mathrm{C}-3$ Bioengineering, The University of lowa). The short-circuit current $\left(I_{\mathrm{sc}}\right)$ was recorded in the absence of PD after appropriate corrections for the resistance of the fluid between the two PD-sensing bridges. Conductance $(G)$ was calculated from $I_{\mathrm{sc}}$ and PD. Mucosa-to-serosa $\left(J_{\mathrm{m}-\mathrm{s}}\right)$ and serosa-to-mucosa $\left(J_{\mathrm{s}-\mathrm{m}}\right)$ fluxes were paired employing the $30 \%$ conductance-matching criterion of Walling and Kimberg (13).

After the steady state had been reached $(60 \mathrm{~min}), 30 \mu \mathrm{Ci}$ of ${ }^{45} \mathrm{Ca}^{2+}$ was added to either the serosal or the mucosal side of the paired chambers. 1-ml samples were taken from the "cold" side at 20-min intervals for $1 \mathrm{~h}$. Each aliquot removed was replaced with the same solution without ${ }^{45} \mathrm{Ca}^{2+}$. Each aliquot removed was counted in $5 \mathrm{ml}$ of scintillation fluid (Pico-Fluor TM 30, United Technologies, Packard Instrument Company, Inc., Downers Grove, IL) with an LKB 1212 RackBeta Wallac liquid scintillation counter (LKB Instruments, Gaithersburg, MD). Calcium fluxes were calculated as described by Schultz and Zalusky (14) and expressed as nanomoles $/ \mathrm{cm}^{2}$ per hour. Steady-state values were reached

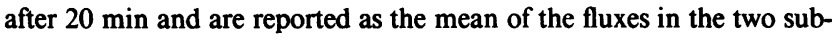
sequent 20-min periods. Net flux was calculated on paired tissues from the same animal $\left(J_{\text {net }}=J_{\text {m-s }}-J_{\text {s-m }}\right)$.

Fluxes in 12-14-wk-old animals on normal dietary calcium. Nine SHR and nine WKY were raised from the age of $6 \mathrm{wk}$ to the age of 1214 wk on $1.0 \%$ calcium diets identical to those taken by the animals in which vitamin $D_{3}$ determinations were carried out. Unidirectional fluxes were determined in the Ussing chamber apparatus as described above.

Fluxes in 12-14-wk-old animals on reduced dietary calcium. Six SHR and six WKY were raised from the age of $6 \mathrm{wk}$ to the age of 12-14 wk on $0.1 \%$ calcium diets identical to those taken by the animals in which vitamin $\mathrm{D}_{3}$ determinations were carried out. Unidirectional fluxes were determined in the Ussing chamber apparatus as described above.

Fluxes in 20-24-wk animals on normal and reduced dietary calcium. Five SHR and four WKY rats were raised to the age of 20-24 wk on diets identical to that described above ( $1 \%$ calcium). They were then sacrificed and calcium fluxes measured by the Ussing chamber technique. Seven WKY and seven SHR were raised to the same age on diets identical in all respects apart from their $0.1 \%$ calcium content. Their intestinal calcium fluxes were then measured as described above.

Administration of $1,25(\mathrm{OH})_{2} D_{3}$ to $S H R$. Four SHR were raised to the age of 12-14 wk on normal dietary calcium (1\%) identical to that described above. $115 \mathrm{ng}$ of $(275 \mathrm{pmol}) 1,25(\mathrm{OH})_{2} \mathrm{D}_{3}$ was administered intraperitoneally in $50 \mu \mathrm{l}$ of propylene glycol (15) daily for $4 \mathrm{~d}$ prior to sacrifice. Unidirectional calcium fluxes were then determined as described above.

Bone mineral analysis in vivo. $14 \mathrm{SHR}$ and $13 \mathrm{WKY}$ were raised on a $1.0 \%$ calcium diet, identical to that taken by the animals in the vitamin $\mathrm{D}$ and Ussing chamber studies (Teklad, Madison, WI). At the age of 23 wk, bone mineral content was measured by the method reported by Sanchez et al. (16), utilizing direct photon absorptiometry (model 278c; Norland Instruments, Fort Atkinson, WI). Each measurement represents the mean of five scans of the left femur of each animal and is expressed as bone mineral content/femur width (BMC/W) in grams per $\mathrm{cm}^{2}$.

Bone mineral analysis in vitro. Five SHR and seven WKY were raised on $1.0 \%$ calcium diets, identical to that taken by the animals in the vitamin D and Ussing chamber studies, to the age of $31 \mathrm{wk}$. After sacrifice, the left femur was excised, soft tissue was removed, and the bone was dried and ashed. Total calcium content (milligrams per gram of dry weight) was determined by atomic absorption (Varian Instruments, Sunnyvale, CA).

Statistics. All between-group comparisons were made utilizing the Mann-Whitney $U$ test apart from the in vivo BMC/W comparisons for which the two-tailed $t$ test for nonpaired observations was employed. Results are expressed throughout as mean \pm standard error of the mean.

\section{Results}

Circulating levels of vitamin $D_{3}$ metabolites. Serum levels of $1,25(\mathrm{OH})_{2} \mathrm{D}_{3}$ were significantly lower in SHR than in WKY controls at the age of 12-14 wk on a normal (1\%) calcium diet, $P<0.005$. A low calcium regime $(0.1 \%)$ administered to animals 12-14 wk of age was associated with $\sim 80 \%$ increased serum $1,25(\mathrm{OH})_{2} \mathrm{D}_{3}$ values in both SHR and WKY, resulting in significantly lower values in the SHR compared with the corresponding WKY, $P<0.001$. In both the normal and the low calcium groups, the mean circulating level of $1,25(\mathrm{OH})_{2} \mathrm{D}_{3}$ in the SHR was $\sim 60 \%$ of that observed in the WKY (Fig. 1). For both SHR and WKY, the difference between $1,25(\mathrm{OH})_{2} \mathrm{D}_{3}$ levels on the normal and low calcium regimes, was highly significant $(P<0.002)$. In contrast to circulating $1,25(\mathrm{OH})_{2} \mathrm{D}_{3}$, serum levels of $25(\mathrm{OH}) \mathrm{D}_{3}$ did not differ significantly between the SHR and the WKY on $1 \%$ calcium $(31.0 \pm 1.3$ vs. $27.5 \pm 1.1 \mathrm{ng} / \mathrm{ml}, n=$ eight pairs, $P=\mathrm{NS})$ or $0.1 \%$ calcium $(26.2 \pm 0.9$ vs. $26.7 \pm 1.6 \mathrm{ng} / \mathrm{ml}$, $n=$ eight pairs, $P=\mathrm{NS}$ ). For the SHR on a $1 \%$ calcium diet there was a positive correlation between $1,25(\mathrm{OH})_{2} \mathrm{D}_{3}$ and $25(\mathrm{OH}) \mathrm{D}_{3}: r=0.83, P<0.01$, which was not found in the WKY on the $1 \%$ calcium diet nor in either strain on $0.1 \%$ calcium.

Studies of intestinal calcium transport. In the 12-14-wk-old animals on $1 \%$ calcium, duodenal $J_{\mathrm{m}-\mathrm{s}}$ (Fig. 2) and $J_{\text {net }}$ for calcium were significantly lower in the SHR than in the WKY, $P<0.02$, whereas $J_{\text {s-m }}$ did not differ significantly (data from McCarron et al. [10] and additional determinations). Similarly, in 12-14-wkold animals on $0.1 \%$ calcium, duodenal $J_{\text {m-s }}$ (Fig. 2) and $J_{\text {net }}$ for calcium were significantly lower in the SHR than in the WKY, $P<0.002$, whereas $J_{\text {s-m }}$ did not differ significantly. In parallel with the changes seen in mean serum $1,25(\mathrm{OH})_{2} \mathrm{D}_{3}$ levels, calcium deprivation increased mean $J_{\mathrm{m}-\mathrm{s}}$ by $\sim 80 \%$ in both strains. Furthermore, in both the normal and the low calcium groups, the mean $J_{\mathrm{m}-\mathrm{s}}$ in the SHR was also $\sim 60 \%$ of that observed in the WKY (Fig. 2).

Comparing the responses to low dietary calcium at the age of 20-24 wk in the SHR and WKY, there was a small increase in duodenal $J_{\mathrm{m}-\mathrm{s}}$, from $29.5 \pm 4.2$ on $1 \%$ calcium to $37.2 \pm 8.1$ 


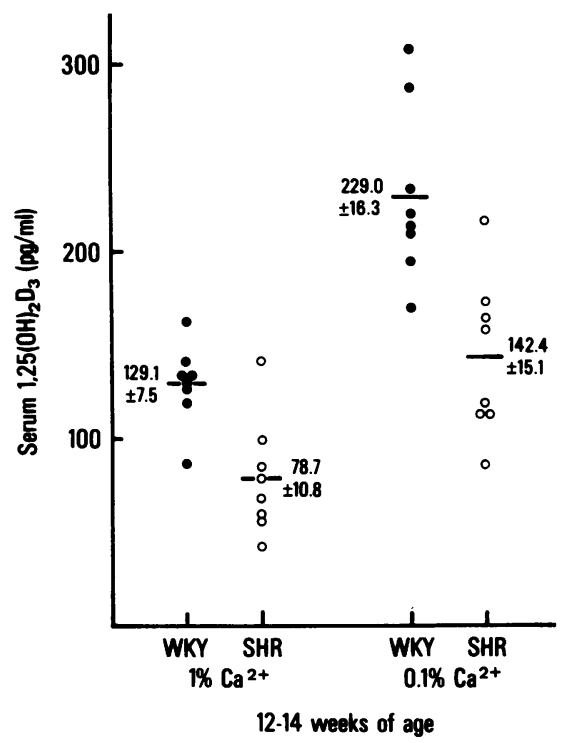

Figure 1. Circulating 1,25(OH $)_{2} \mathrm{D}_{3}$ in 12-14-wk-old WKY and SHR raised on $1 \%$ and $0.1 \%$ calcium diets. Results are expressed as mean \pm SEM. On each regimen, serum $1,25(\mathrm{OH})_{2} \mathrm{D}_{3}$ was significantly lower in the SHR than in the WKY $(P<0.005)$. For each rat strain, low dietary calcium was associated with a significant increase in serum $1,25(\mathrm{OH})_{2} \mathrm{D}_{3}(P<0.002)$.

$\mathrm{nmol} / \mathrm{cm}^{2} \cdot \mathrm{h}$ on $0.1 \%$ calcium (NS) in the SHR, whereas a significant increase occurred in the WKY, from $30.6 \pm 4.0$ on $1 \%$ calcium to $83.1 \pm 10.5 \mathrm{nmol} / \mathrm{cm}^{2} \cdot \mathrm{h}$ on $0.1 \%$ calcium $(P<0.01)$. Thus in SHR of 20-24 weeks of age, dietary calcium deprivation was associated with lower $J_{\mathrm{m}-\mathrm{s}}$ than that observed in correspond-

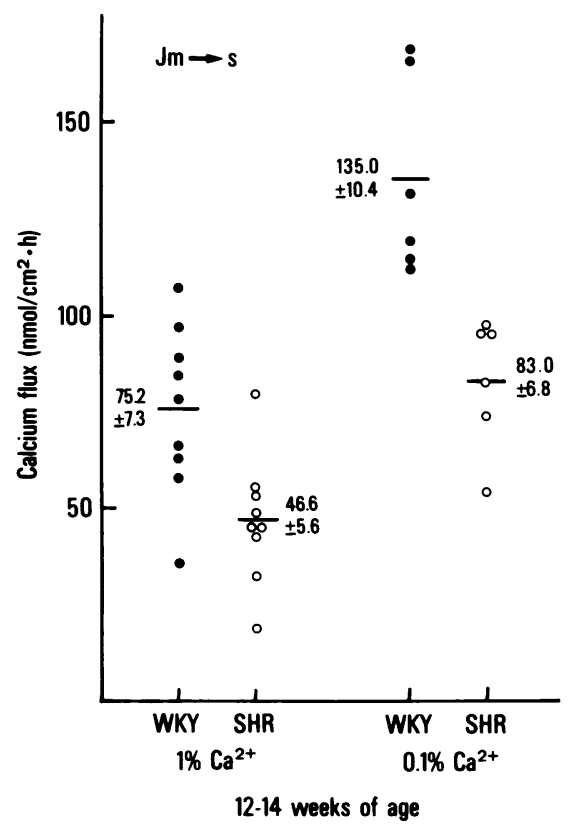

Figure 2. Mucosa-to-serosa calcium flux $\left(J_{\mathrm{m}-\mathrm{s}}\right)$ measured in the Ussing chamber in duodena from 12-14-wk-old WKY and SHR raised on $1 \%$ and $0.1 \%$ dietary calcium. Results are expressed as mean \pm SEM. $J_{\mathrm{m}-\mathrm{s}}$ was significantly lower in the SHR than in the WKY on $1 \%$ calcium, $P<0.02$, and on $0.1 \%$ calcium, $P<0.002$. For corresponding $J_{s-\mathrm{m}}$ and $J_{\text {net }}$, see Table I. ing WKY, $P<0.005$ (Fig. 3). Administration of $1,25(\mathrm{OH})_{2} \mathrm{D}_{3}$ to the 12-14-wk-old SHR raised on $1 \%$ calcium was associated with a mean duodenal $J_{\mathrm{m}-\mathrm{s}}$ of $100.1 \pm 20.1 \mathrm{nmol} / \mathrm{cm}^{2} \cdot \mathrm{h}$, significantly higher than in corresponding untreated SHR, $P<0.01$ (Table I) and indicating an intestinal response to exogenous $1,25(\mathrm{OH})_{2} \mathrm{D}_{3}$.

Short circuit current $\left(I_{\mathrm{sc}}\right)$, recorded after a 60 -min equilibration, was significantly lower in SHR of 12-14 wk of age on $0.1 \%$ calcium and in the 20-24-wk-old SHR on $1 \%$ and $0.1 \%$ calcium than in the corresponding WKY. Lower dietary calcium led to significant reductions in $I_{\mathrm{sc}}$ in both WKY and SHR of 20-24 wk of age. The difference between SHR and WKY in animals on $1 \%$ dietary calcium did not reach statistical significance. Although at present a matter for speculation, the lower $I_{\mathrm{sc}}$ in the SHR could reflect differences in intestinal transport of sodium, which could be related to the differences in circulating $1,25(\mathrm{OH})_{2} \mathrm{D}_{3}(17)$ or possibly to differences in intracellular calcium concentration (18).

Bone densitometry and calcium content. Both in vivo and in vitro parameters of bone calcium status were significantly reduced in the SHR compared with WKY. Bone density, expressed as the ratio of mineral content to width of the rat femur, measured in vivo in animals of $23 \mathrm{wk}$ of age, was $0.231 \pm 0.004$ $\mathrm{g} / \mathrm{cm}^{2}$ in the SHR compared with $0.244 \pm 0.004 \mathrm{~g} / \mathrm{cm}^{2}$ in the WKY, $P<0.001$ (Fig. 4). Bone calcium content, determined after sacrifice at $31 \mathrm{wk}$ of age, was $220.9 \pm 2.1 \mathrm{mg}$ calcium/g dry bone in the SHR compared with $269.7 \pm 5.2 \mathrm{mg}$ calcium/g dry bone in the WKY, $P<0.002$ (Fig. 4).

Body weights of animals used in studies. There was no consistent pattern in the differences between the mean weights of SHR and WKY in the groups studied and differences observed between weights of SHR and WKY were not significantly different (Table II).

\section{Discussion}

The present report documents the finding of reduced circulating $1,25(\mathrm{OH})_{2} \mathrm{D}_{3}$ levels as well as decreased duodenal $J_{\mathrm{m}-\mathrm{s}}$ and $J_{\text {net }}$

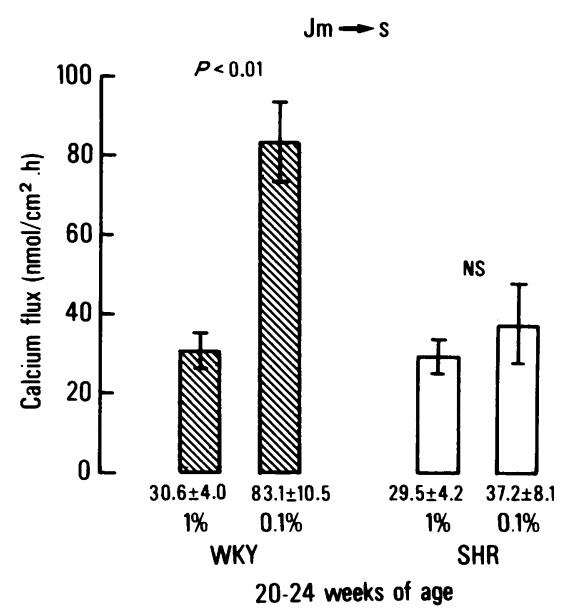

Figure 3. Mucosa-to-serosa calcium flux $\left(J_{\mathrm{m}-\mathrm{s}}\right)$ in duodena from 20-24-wk-old WKY and SHR raised on $1 \%$ and $0.1 \%$ dietary calcium. Results are expressed as mean \pm SEM. On $1 \%$ dietary calcium $J_{\mathrm{m}-\mathrm{s}}$ did not differ between SHR and WKY. On $0.1 \%$ calcium, the difference was significant, $P<0.005$. Low dietary calcium was associated with a significant increase in $J_{\mathrm{m}-\mathrm{s}}$ in the WKY, $P<0.01$, but not in the SHR. For corresponding $J_{\text {s-m }}$ and $J_{\text {net }}$, see Table I. 
Table I. Ussing Chamber Determinations of Intestinal Calcium Fluxes, Short Circuit Current and Electrical Conductance

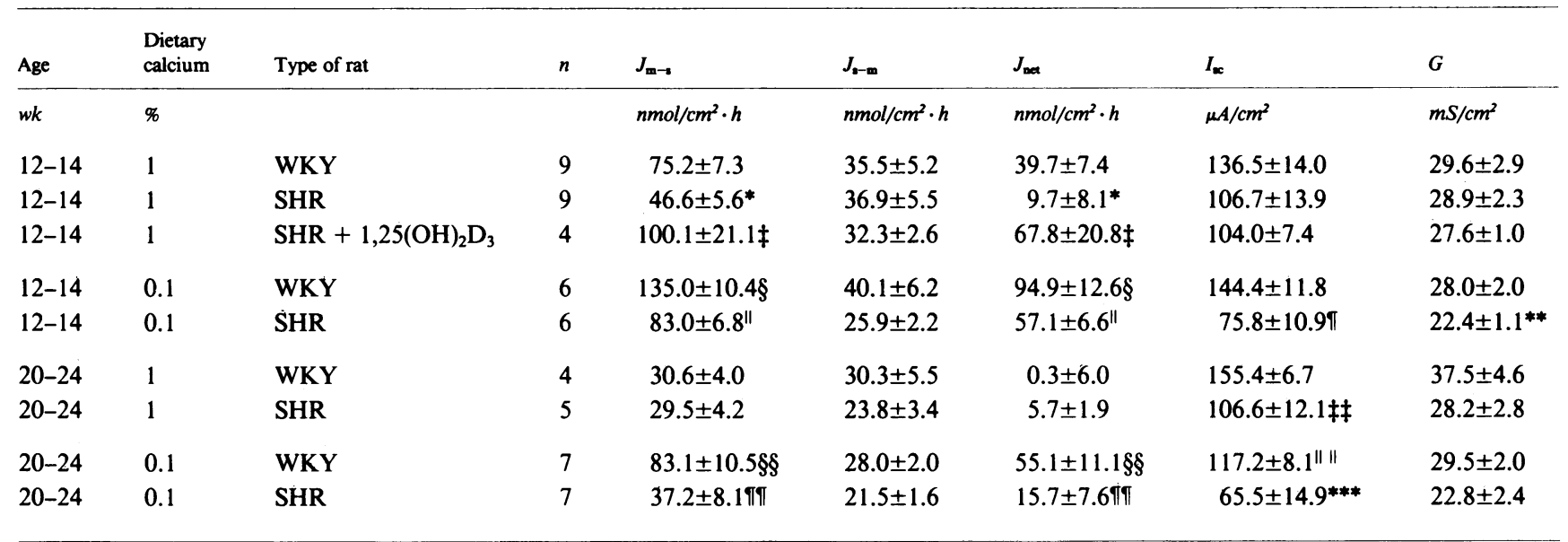

${ }^{*} P<0.02$ vs. WKY. $\ddagger P<0.01$ vs. untreated SHR. $\S P<0.002$ vs. WKY on $1 \%$ calcium. $\| P<0.005$ vs. WKY on $0.1 \%, P<0.002$ vs. SHR on $1 \%$ calcium. $\pi P<0.002$ vs. WKY on $0.1 \%$ calcium. ${ }^{* *} P<0.05$ vs. WKY. $\ddagger \ddagger P<0.05$ vs. WKY. $\$ \S P<0.01$ vs. WKY on $1 \%$ calcium. $\|"\|<0.02$ vs. WKY on $1 \%$ calcium. Iा $P<0.005$ vs. WKY on $0.1 \%$ calcium. ${ }^{* * *} P<0.02$ vs. WKY on $0.1 \%$ calcium, $P<0.05$ vs. SHR on $1 \%$ calcium.

for calcium in the 12-14-wk-old SHR compared with the corresponding WKY, both in animals receiving normal dietary calcium $(1 \%)$ and in those receiving low dietary calcium $(0.1 \%)$. Values of both $1,25(\mathrm{OH})_{2} \mathrm{D}_{3}$ and $J_{\mathrm{m}-\mathrm{s}}$ in the SHR were $\sim 60 \%$ of those in the corresponding WKY in both dietary groups, the low calcium diet being associated with an $\sim 80 \%$ increase in $1,25(\mathrm{OH})_{2} \mathrm{D}_{3}$ levels and in $J_{\mathrm{m}-\mathrm{s}}$ in the SHR as well as in the WKY. These data constitute strong evidence in favor of a causal relationship between the reduction in $1,25(\mathrm{OH})_{2} \mathrm{D}_{3}$ levels and the diminished calcium absorption in the SHR. Furthermore, calcium deprivation in the SHR stimulated a rise in endogenous $1,25(\mathrm{OH})_{2} \mathrm{D}_{3}$ to the level observed in the WKY on normal dietary calcium. The fact that this level of $1,25(\mathrm{OH})_{2} \mathrm{D}_{3}$ was associated with an increase in $J_{\mathrm{m}-\mathrm{s}}$ to the value found in the WKY on normal dietary calcium argues strongly against intestinal resistance to the action of $1,25(\mathrm{OH})_{2} \mathrm{D}_{3}$ in the SHR. Exogenous $1,25(\mathrm{OH})_{2} \mathrm{D}_{3}$ corrected the abnormally reduced $J_{\mathrm{m}-\mathrm{s}}$ in the SHR
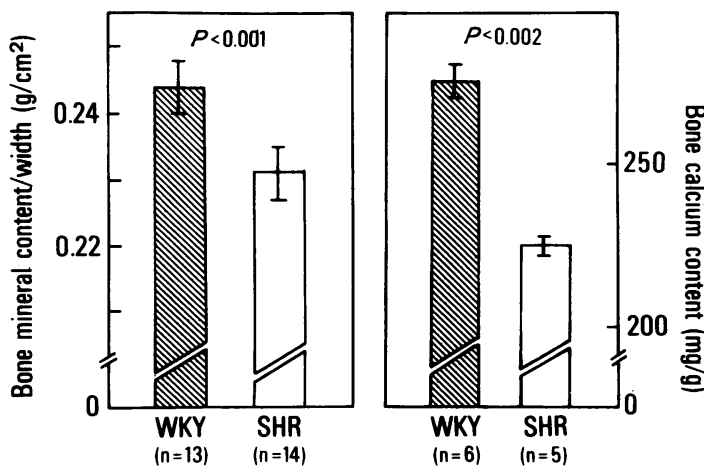

Figure 4. (a) Bone density, expressed as bone mineral content per unit width of femur, measured in vivo in 23-wk-old WKY and SHR raised on diets containing $1 \%$ calcium. Bone density was significantly lower in the SHR than in the WKY. (b) Bone calcium content measured after sacrifice in 31-wk-old WKY and SHR raised on 1\% dietary calcium. Bone calcium content was significantly lower in SHR than in WKY. Results are expressed as mean \pm SEM. although, because of the supraphysiologic dose (19) and nonphysiologic route of administration, interpretation of this observation in terms of intestinal response must remain guarded.

Table II. Body Weights of Animals Used in Vitamin D, Transport, and Bone Mineral Studies

\begin{tabular}{lllll}
\hline Age & $\begin{array}{l}\text { Dietary } \\
\text { calcium }\end{array}$ & Animal & $n$ & Weight \\
\hline$w k$ & $\%$ & & & $g$ \\
Vitamin D & & & & \\
$\begin{array}{l}\text { measurements } \\
12-14\end{array}$ & 1 & WKY & & \\
$12-14$ & 1 & SHR & 8 & $307.6 \pm 7.8$ \\
$12-14$ & 0.1 & WKY & 8 & $295.5 \pm 6.4$ \\
$12-14$ & 0.1 & SHR & 8 & $322.2 \pm 7.5$ \\
Transport studies & & & 8 & $318.0 \pm 8.6$ \\
$12-14$ & 1 & WKY & & \\
$12-14$ & 1 & SHR & 9 & $296.7 \pm 8.3$ \\
$12-14$ & 1 & SHR $+1,25(\mathrm{OH})_{2} \mathrm{D}_{3}$ & 4 & $290.6 \pm 12.1$ \\
$12-14$ & 0.1 & WKY & 9 & $317.0 \pm 10.2$ \\
$12-14$ & 0.1 & SHR & 6 & $332.2 \pm 5.7$ \\
$20-24$ & 1 & WKY & 6 & $321.5 \pm 5.1$ \\
$20-24$ & 1 & SHR & 4 & $432.7 \pm 15.4$ \\
$20-24$ & 0.1 & WKY & 5 & $438.9 \pm 15.3$ \\
$20-24$ & 0.1 & SHR & 7 & $403.6 \pm 8.5$ \\
& & & 7 & $388.6 \pm 11.1$
\end{tabular}

Bone mineral determinations Densitometry (in vivo) 23 23 WKY

$361.0 \pm 6.4$ SHR $14 \quad 341.0 \pm 6.4$

Bone calcium

content (postmortem)

31 31 SHR 
However, it provides no support for the contention that the SHR exhibits intestinal resistance to the action of $1,25(\mathrm{OH})_{2} \mathrm{D}_{3}$.

Toraason and Wright (6), who found no response on administration of a similar quantity $(100 \mathrm{ng})$ of $1,25(\mathrm{OH})_{2} \mathrm{D}_{3}$ to the SHR, found increased, not decreased, transport in the untreated SHR. It is not clear, however, why our results differ from those of Schedl et al. (9), who inferred intestinal resistance in the SHR from their findings of diminished calcium transport and normal levels of $1,25(\mathrm{OH})_{2} \mathrm{D}_{3}$ in the 12-wk-old SHR. Calcium and phosphorus intakes exert profound influences on serum levels of $1,25(\mathrm{OH})_{2} \mathrm{D}_{3}$ in the young rat $(20,21)$, and although the calcium content of the diet used by Schedl et al. (9) was identical to that used in our study (1\%), there was a considerable difference between the phosphorus contents of the two regimes: $0.46 \%$ in our study, compared with $0.74 \%$ in that of Schedl et al. This may help to explain the difference between their findings and ours in terms of $1,25(\mathrm{OH})_{2} \mathrm{D}_{3}$ levels. A further possibly relevant difference is between the vitamin $\mathrm{D}$ content of our diet $(2.2 \mathrm{IU} / \mathrm{g})$ and that of Schedl et al. $(3.3 \mathrm{IU} / \mathrm{g})$. Stern et al. (8), who gave a regimen that provided $0.4 \%$ calcium and $0.9 \%$ phosphate, found a nearly $30 \%$ reduction in $1,25(\mathrm{OH})_{2} \mathrm{D}_{3}$ levels in 10-wk-old SHR compared with WKY of the same age. This difference was not, however, statistically significant (8). In the latter report, details of the quantity of vitamin D administered were not given.

In the present study, no significant difference was observed between the level of $25(\mathrm{OH}) \mathrm{D}_{3}$, the precursor of $1,25(\mathrm{OH})_{2} \mathrm{D}_{3}$, in any of the four groups of animals and the absolute levels $(\sim 30 \mathrm{ng} / \mathrm{ml})$ were similar to those reported by Schedl et al. (9), suggesting that lower $1,25(\mathrm{OH})_{2} \mathrm{D}_{3}$ in the SHR was not the result of insufficient substrate. The question of whether reduced production or enhanced degradation of $1,25(\mathrm{OH})_{2} \mathrm{D}_{3}$ is responsible for the lower circulating levels is as yet unresolved. Increased catabolism of $1,25(\mathrm{OH})_{2} \mathrm{D}_{3}$ does occur in specific circumstances in the normal rat $(22,23)$, but the finding of Schedl et al. that $25(\mathrm{OH}) \mathrm{D}_{3}$ was higher in the SHR than in the WKY (9) might suggest the former to be more probable. The $80 \%$ increase in $1,25(\mathrm{OH})_{2} \mathrm{D}_{3}$ levels, occurring in response to calcium deprivation in the SHR as well as the WKY, suggest that there is unlikely to be an intrinsic abnormality of $25(\mathrm{OH}) \mathrm{D}_{3}-1 \alpha$-hydroxylase in the SHR. It further indicates that substantial reduction in dietary calcium did not change the factor(s) responsible for the lower levels of $1,25(\mathrm{OH})_{2} \mathrm{D}_{3}$ in the SHR.

The striking parallelism noted above between $1,25(\mathrm{OH})_{2} \mathrm{D}_{3}$ and $J_{\mathrm{m}-\mathrm{s}}$ in the 12-14-wk-old SHR and WKY suggests that reduced $1,25(\mathrm{OH})_{2} \mathrm{D}_{3}$ in the SHR is the cause of its decreased $J_{\mathrm{m}-\mathrm{s}}$, particularly inasmuch as this component of calcium transport is known to be $1,25(\mathrm{OH})_{2} \mathrm{D}_{3}$-dependent in normal rats $(24$, 25). The observation that the response of the 20-24-wk-old SHR $J_{\mathrm{m}-\mathrm{s}}$ to low dietary calcium was significantly impaired compared to that of the WKY (Fig. 3) is best explained by the hypothesis that the calcium-deprived 20-24-wk-old SHR is also unable to sustain appropriate levels of $1,25(\mathrm{OH})_{2} \mathrm{D}_{3}$. Normal rats are able to respond to calcium deprivation by increasing their $1,25(\mathrm{OH})_{2} \mathrm{D}_{3}$ levels at least until the age of $25 \mathrm{mo}(21)$ and the calcium-deprived 20-24-wk-old WKY in this study significantly increased $J_{\mathrm{m}-\mathrm{s}}$, a process known to be $1,25(\mathrm{OH})_{2} \mathrm{D}_{3}$ dependent $(26,27)$. The finding of similar $J_{\mathrm{m}-\mathrm{s}}$ in the 20-24-wk-old SHR and WKY on normal dietary calcium, significantly below that found in the 12-14-wk-old WKY on $1 \%$ calcium, can be explained on the basis of the fact that by the age of $21-22 \mathrm{wk}$, in the normal rat on normal dietary calcium, almost all duodenal calcium transport occurs by a nonsaturable $1,25(\mathrm{OH})_{2} \mathrm{D}_{3}$-independent route (28). In regard to the decrease in active duodenal calcium transport with age in the normal rat, our observations are in accord with those of other investigators $(26,28)$.

Thus we have found evidence for reduced baseline and stimulated serum $1,25(\mathrm{OH})_{2} \mathrm{D}_{3}$ levels in the 12-14-wk-old SHR, as well as for reduced baseline and stimulated $1,25(\mathrm{OH})_{2} \mathrm{D}_{3}$-dependent functions in the SHR at 12-14 wk and at 20-24 wk. Whereas it is probable that these differences represent abnormalities in calcium metabolism, it is theoretically a possibility that they could be appropriate responses to a difference in calcium status in the SHR compared with the WKY. Our findings in terms of parameters of bone calcium status in the SHR do not support this latter hypothesis. Reduced bone density, expressed as BMC/W (16), and reduced bone calcium content in the SHR suggest, on the contrary, that the decreased $1,25(\mathrm{OH})_{2} \mathrm{D}_{3}$-dependent component of intestinal calcium transport may have contributed to a smaller increase in body calcium content with age, in the SHR compared with the WKY. In this, our findings are similar to those of Izawa et al. (29), who found reduced indexes of bone calcium content and cortical size in 26-wk-old male SHR fed similar quantities of vitamin D to our animals. Our data differ from those of Lau et al. (7), who found increased bone calcium content in the 52-wk-old female SHR compared with WKY. Apart from the difference in sex, there are major differences between the dietary regime supplied in the two studies, most notably the administration by Lau et al. of 5.6 IU vitamin D per gram of food, a 2.5 -fold greater quantity than that received by ours. Our data on serum vitamin $D_{3}$ metabolites indicated that in 12-14-wk-old animals fed $1 \%$ calcium, there was a positive correlation between serum $25(\mathrm{OH}) \mathrm{D}_{3}$ and $1,25(\mathrm{OH})_{2} \mathrm{D}_{3}$ in the SHR which we did not find in the WKY. If, in the study reported by Lau et al. (7), the $25(\mathrm{OH}) \mathrm{D}_{3}-1 \alpha$ hydroxylase in the SHR exhibited such substrate dependence but that in the WKY did not, the differences between their findings and ours might be explained.

The mechanism underlying the reduced $1,25(\mathrm{OH})_{2} \mathrm{D}_{3}$ levels in the SHR remains a matter for speculation. If reduced production is indeed responsible, it is not diminished on account of reduced renal function, as this is indistinguishable in the SHR from that of the WKY at the age of 12-14 wk, despite higher arterial blood pressure (30). Reduced $1,25(\mathrm{OH})_{2} \mathrm{D}_{3}$ production could result from a primary perturbation in intracellular calcium handling (31) which resulted in, for example, raised intramitochondrial free calcium levels (32) and inhibition of $25(\mathrm{OH}) \mathrm{D}_{3}$ $1 \alpha$-hydroxylase $(33,34)$. Alternatively, the SHR's $25(\mathrm{OH}) \mathrm{D}_{3}$ $1 \alpha$-hydroxylase itself may be abnormal, although, as suggested above, its response to reduced dietary calcium would argue against this.

The fact that the SHR has lower circulating $1,25(\mathrm{OH})_{2} \mathrm{D}_{3}$ than the WKY under certain conditions, may provide an explanation for some of the multiplicity of abnormalities of calcium and phosphate handling it appears to exhibit. Reduction in plasma ionized calcium and raised plasma parathyroid hormone in the $\operatorname{SHR}(4,5,8)$ might, for example, result from diminished intestinal absorption caused by lower circulating $1,25(\mathrm{OH})_{2} \mathrm{D}_{3}$ levels. Similarly, hypercalciuria in the SHR (7) might be explicable on the basis of recent evidence that vitamin $\mathrm{D}$ appears to promote renal tubular reabsorption of calcium (35). There is also increasing evidence that renal tubular phosphate reabsorp- 
tion is abnormally elevated in the $\operatorname{SHR}(36,37)$. As $1,25(\mathrm{OH})_{2} \mathrm{D}_{3}$ stimulates intestinal absorption of phosphorus $(38,39)$, a relative deficiency might be associated with reduced intestinal absorption of phosphorus and lead to decreased urinary phosphate excretion (40) even in the presence of elevated plasma parathyroid hormone. Decreased $1,25(\mathrm{OH})_{2} \mathrm{D}_{3}$ might also explain the recent finding of Kowarski et al. (41) of reduced tissue content of integral membrane calcium-binding protein in tissues of the SHR (41) as this protein has been established to be vitamin D-dependent (42). The $\sim 40 \%$ reduction in duodenal mucosal integral membrane calcium-binding protein content in the SHR relative to the WKY, corresponds closely to the reduction in circulating $1,25(\mathrm{OH})_{2} \mathrm{D}_{3}$ and $J_{\mathrm{m}-\mathrm{s}}$ in the SHR documented in the present report.

In summary, we have found direct evidence in the SHR, of reduced circulating levels of the hormone, $1,25(\mathrm{OH})_{2} \mathrm{D}_{3}$, both before and after stimulation by low dietary calcium. We have observed a reduction in baseline and stimulated active intestinal calcium transport in this animal at the age of 12-14 wk, almost certainly as a consequence. We have observed the impairment of the ability of the older SHR to adapt to calcium deprivation. Finally, we have demonstrated the inappropriateness of reduced $1,25(\mathrm{OH})_{2} \mathrm{D}_{3}$ levels and reduced calcium absorption in terms of the bone calcium status of the SHR. These data suggest that the SHR is a naturally occurring model of disturbed $1,25(\mathrm{OH})_{2} \mathrm{D}_{3}$ metabolism. Greater understanding of the mechanisms involved may have far-reaching implications for the study of the calcium endocrine system, for the understanding of the pathogenesis of increased arterial blood pressure and for elucidation of the increasingly recognized connections between these areas of investigation $(43,44)$.

\section{Acknowledgments}

The authors acknowledge the excellent technical assistance of Lydie Berthet in experiments involving the Ussing chamber, and that of AnneSophie Martin and Patricia Duchambon in other aspects of the work reported. Dr. Lucas was the recipient of a Medical Research Council (United Kingdom) French exchange fellowship and of an award from the Fondation pour la Recherche Médicale (France). Dr. McCarron was the recipient of a Fogarty Travelling Fellowship.

\section{References}

1. Postnov, Y. V., S. N. Orlov, and N. I. Pokudin. 1979. Decrease of calcium binding by the red blood cell membrane in spontaneously hypertensive rats and in essential hypertension. Pflügers Arch. Eur. J. Physiol. 379:191-195.

2. Devynck, M.-A., M.-G. Pernollet, A.-M. Nunez, and P. Meyer. 1981. Analysis of calcium handling in erythrocyte membranes of genetically hypertensive rats. Hypertension. 3:397-403.

3. Noon, J. P., P. J. Rice, and R. J. Baldessarini. 1978. Calcium leakage as a cause of the high resting tension in vascular smooth muscle from the spontaneously hypertensive rat. Proc. Natl. Acad. Sci. USA. 75:1605-1607.

4. Wright, G. L., and G. O. Rankin. 1982. Concentrations of ionic and total calcium in plasma of four models of hypertension. Am. J. Physiol. 243:H365-H370.

5. McCarron, D. A., N. N. Yung, B. A. Ugoretz, and S. Krutzik. 1981. Disturbances of calcium metabolism in the spontaneously hypertensive rat. Hypertension. 3(Suppl. I):I-162-I-167.

6. Toraason, M. A., and G. L. Wright. 1981. Transport of calcium by duodenum of spontaneously hypertensive rat. Am. J. Physiol. 241: G344-G347.
7. Lau, K., J. Zikos, J. Spirnak, and B. Eby. 1984. Evidence for an intestinal mechanism in hypercalciuria of the spontaneously hypertensive rat. Am. J. Physiol. 247:E625-E633.

8. Stern, N., D. B. N. Lee, V. Silis, F. W. Beck, L. Deftos, S. C. Manolagas, and J. R. Sowers. 1984. Effects of high calcium intake on blood pressure and calcium metabolism in young SHR. Hypertension. 6:639-646.

9. Schedl, H. P., D. L. Miller, J. M. Pape, R. L. Horst, and H. D. Wilson. 1984. Calcium and sodium transport and vitamin D metabolism in the spontaneously hypertensive rat. J. Clin. Invest. 73:980-986.

10. McCarron, D. A., P. A. Lucas, R. J. Shneidman, B. Lacour, and T. Drüeke. 1985. Blood pressure development of the spontaneously hypertensive rat following concurrent manipulations of dietary $\mathrm{Ca}^{2+}$ and $\mathrm{Na}^{+}$: relation to intestinal Ca ${ }^{2+}$ fluxes. J. Clin. Invest. 76:1147-1154.

11. Kao, P. C., and D. W. Heser. 1984. Simultaneous determination of 25-hydroxy- and 1,25-dihydroxyvitamin $\mathrm{D}$ from a single sample by dual-cartridge extraction. Clin. Chem. 30:56-61.

12. Walling, M. W., and D. V. Kimberg. 1973. Active secretion of calcium by adult rat ileum and jejunum in vitro. Am. J. Physiol. 225: 415-422.

13. Walling, M. W., and D. V. Kimberg. 1978. Effects of 1,25-dihydroxyvitamin $\mathrm{D}_{3}$ and Solanum glaucophyllum on intestinal calcium and phosphate transport and on plasma $\mathrm{Ca}, \mathrm{Mg}$, and phosphorus levels in the rat. Endocrinology. 97:1567-1576.

14. Schulz, S. G., and R. Zalusky. 1964. Ion transport in isolated rabbit ileum, short circuit current and $\mathrm{Na}^{+}$fluxes. J. Gen. Physiol. 47: $567-587$.

15. Hefti, E., U. Trechsel, H. Fleisch, and J. P. Bonjour. 1983. Nature of calcaemic effect of 1,25-dihydroxyvitamin $D_{3}$ in experimental hypoparathyroidism. Am. J. Physiol. 244:E313-E316.

16. Sanchez, T. V., R. C. Myers, J. T. Bond, and G. H. Mayor. 1981. Bone mineral analysis of the rat femur by direct photon absorptiometry. Calcif. Tissue Int. 33:587-590.

17. Favus, M. J., E. Angeid-Backman, M. D. Breyer, and F. L. Coe. 1983. Effects of trifluoperazine, ouabain, and ethacrynic acid on intestinal calcium transport. Am. J. Physiol. 244:G111-G115.

18. Donowitz, M. 1983. $\mathrm{Ca}^{2+}$ in the control of active intestinal $\mathrm{Na}$ and $\mathrm{Cl}$ transport: involvement in neurohumoral action. Am. J. Physiol. 245:G165-G177.

19. Rizzoli, R., H. Fleisch, and J. P. Bonjour. 1977. Effect of thyroparathyroidectomy on calcium metabolism in rats: role of 1,25-dihydroxyvitamin $\mathrm{D}_{3}$. Am. J. Physiol. 233:E160-E164.

20. Rader, J. I., D. J. Baylink, M. R. Hughes, E. F. Safilian, and M. R. Haussler. 1979. Calcium and phosphorus deficiency in rats: effects on PTH and 1,25-dihydroxyvitamin $\mathrm{D}_{3}$. Am. J. Physiol. 236:E118-E122.

21. Armbrecht, H. J., L. R. Forte, and B. P. Halloran. 1984. Effect of age and dietary calcium on renal $25(\mathrm{OH}) \mathrm{D}$ metabolism, serum 1,25(OH $)_{2}$ D, and PTH. Am. J. Physiol. 246:E266-E270.

22. Frolik, C. A., and H. F. DeLuca. 1973. The stimulation of 1,25dihydroxycholecalciferol metabolism in vitamin D-deficient rats by 1,25 dihydroxycholecalciferol treatment. J. Clin. Invest. 52:543-548.

23. Favus, M. J., and C. B. Langman. 1984. Effects of 1,25-dihydroxyvitamin $\mathrm{D}_{3}$ on colonic calcium transport in vitamin D-deficient and normal rats. Am. J. Physiol. 246:G268-G273.

24. Walling, M. W., D. L. Hartenbower, J. W. Coburn, and A. W. Norman. 1977. Effects of 1,25-, 24R,25-, and 1,24R,25-hydroxylated metabolites of vitamin $\mathrm{D}_{3}$ on calcium and phosphate absorption by duodenum from intact and nephrectomised rats. Arch. Biochem. Biophys. 182:251-257.

25. Lee, D. B. N., M. W. Walling, B. S. Levine, U. Gafter, V. Silis, A. Hodsman, and J. W. Coburn. 1981. Intestinal and metabolic effect of 1,25-dihydroxyvitamin $\mathrm{D}_{3}$ in normal adult rat. Am. J. Physiol. 240: G90-G96.

26. Horst, R. L., H. F. DeLuca, and N. A. Jorgensen. 1978. The effect of age on calcium absorption and accumulation of 1,25-dihydroxyvitamin $\mathrm{D}_{3}$ in intestinal mucosa of rats. Metab. Bone Dis. \& Rel. Res. 1:29-33. 
27. Swaminathan, R., B. A. Sommerville, and A. D. Care. 1977. The effect of dietary calcium on the activity of 25-hydroxycholecalciferol-1hydroxylase and $\mathrm{Ca}$ absorption in vitamin D-replete chicks. Br. J. Nutr. 38:47-54.

28. Pansu, D., C. Bellaton, and F. Bronner. 1983. Developmental changes in the mechanisms of duodenal calcium transport in the rat. Am. J. Physiol. 244:G20-G26.

29. Izawa, Y., K. Sagara, T. Kadota, and T. Makita. 1985. Bone disorders in spontaneously hypertensive rat. Calcif. Tissue Int. 37:605607.

30. Beierwaltes, W. H., and W. J. Arendshorst. 1978. Renal function of conscious spontaneously hypertensive rats. Circ. Res. 42:721-726.

31. Bruschi, G., M. E. Bruschi, M. Caroppo, G. Orlandini, M. Spaggiari, and A. Cavatorta. 1985. Cytoplasmic free $\left[\mathrm{Ca}^{2+}\right]$ is increased in the platelets of spontaneously hypertensive rats and essential hypertensive patients. Clin. Sci. (Lond.). 68:179-184.

32. Postnov, Y. V., and S. N. Orlov. 1979. Features of intracellular calcium distribution in the adipose tissue of spontaneously hypertensive rats. Experientia (Basel). 35:1480-1481.

33. Bikle, D. D., and H. Rasmussen. 1975. The ionic control of 1,25dihydroxyvitamin $\mathrm{D}_{3}$ production in isolated chick renal tubules. J. Clin. Invest. 55:292-298.

34. Trechsel, U., J. A. Eisman, J. A. Fischer, J.-P. Bonjour, and H. Fleisch. 1980. Calcium-dependent, parathyroid hormone-independent regulation of 1,25-dihydroxyvitamin D. Am. J. Physiol. 239:E119-E124.

35. Yamamoto, M., Y. Kawanobe, H. Takahashi, E. Shimazawa, S. Kimura, and E. Ogata. 1984. Vitamin D deficiency and renal calcium transport in the rat. J. Clin. Invest. 74:507-513.
36. Hsu, C. H., P. S. Chen, and R. M. Caldwell. 1984. Renal phosphate excretion in spontaneously hypertensive and normotensive Wistar-Kyoto rats. Kidney Int. 25:789-795.

37. Bindels, R. J., J. A. Geertsen, and C. H. van Os. 1986. Increased transport of inorganic phosphate in renal brush borders of spontaneously hypertensive rats. Am. J. Physiol. 250:F470-F475.

38. Tanaka, Y., and H. F. DeLuca. 1974. Role of 1,25-dihydroxyvitamin $\mathrm{D}_{3}$ in maintaining serum phosphorus and curing rickets. Proc. Natl. Acad. Sci. USA. 71:1040-1044.

39. Peterlik, M., and R. H. Wasserman. 1978. Effect of vitamin D on transepithelial phosphate transport in chick intestine. Am. J. Physiol. 234:E379-E388.

40. Tröhler, U., J.-P. Bonjour, and H. Fleisch. 1976. Inorganic phosphate homeostasis: renal adaptation to the dietary intake in intact and thyroparathyroidectomized rats. J. Clin. Invest. 57:264-273.

41. Kowarski, S., L. A. Cowen, and D. Schachter. 1986. Decreased content of integral membrane calcium-binding protein (IMCAL) in tissues of the spontaneously hypertensive rat. Proc. Natl. Acad. Sci. USA. 83: 1097-1100.

42. Kowarski, S., and D. Schachter. 1980. Intestinal membrane calcium-binding protein; vitamin D-dependent membrane component of the intestinal calcium transport mechanism. J. Biol. Chem. 255:1083410840.

43. Resnick, L. M., L. H. Laragh, J. E. Sealey, and M. H. Alderman. 1983. Divalent cations in essential hypertension: relations between serum ionized calcium, magnesium and plasma renin activity. N. Engl. J. Med. 309:888-891.

44. McCarron, D. A. 1985. Is calcium more important than sodium in the pathogenesis of essential hypertension? Hypertension. 7:607-627. 